\title{
Association between ambient air pollution and mortality from chronic obstructive pulmonary disease in Wuhan, China: a population-based time-series study
}

\author{
Yaqiong Yan ${ }^{1} \cdot$ Lu She $^{2,3} \cdot$ Yan Guo ${ }^{1}$ - Yuanyuan Zhao ${ }^{1} \cdot$ Pei Zhang ${ }^{2,3} \cdot$ Bing Xiang $^{2,3} \cdot$ Jing Zeng ${ }^{2,3}$. \\ Mei Yang ${ }^{2,3}$ (1) $\cdot$ Liang Wang ${ }^{1}$
}

Received: 9 December 2020 / Accepted: 22 February 2021 / Published online: 1 March 2021

(C) The Author(s), under exclusive licence to Springer-Verlag GmbH, DE part of Springer Nature 2021

\begin{abstract}
Evidence on the short-term effects of ambient air pollution on chronic obstructive pulmonary disease (COPD) mortality is still not conclusive. The aim of this study was to investigate the relationships between them in Wuhan China. Daily death numbers, concentrations of air pollutants $\left(\mathrm{PM}_{2.5}, \mathrm{PM}_{10}, \mathrm{SO}_{2}, \mathrm{NO}_{2}\right.$, and $\left.\mathrm{O}_{3}\right)$, and meteorological characteristics in Wuhan from January 1 , 2014, to December 31, 2019, were collected. Time-series analysis using generalized additive model was applied. The results showed that a total of 16,150 deaths (7.37 deaths per day) from COPD were observed. The daily average concentrations of $\mathrm{PM}_{2.5}$, $\mathrm{PM}_{10}, \mathrm{SO}_{2}, \mathrm{NO}_{2}$, and $\mathrm{O}_{3}$ were $59.03,90.48,12.91,48.84$, and $91.77 \mu \mathrm{g} / \mathrm{m}^{3}$, respectively. In single pollutant model, for every increase of $10 \mu \mathrm{g} / \mathrm{m}^{3}$ in $\mathrm{PM}_{10}, \mathrm{SO}_{2}$, and $\mathrm{NO}_{2}$ levels, COPD mortality increased by $0.583 \%$ (95\% CI: $0.055-1.113 \%$ ), $4.299 \%$ (95\% CI: $0.978-7.729 \%)$, and $1.816 \%$ (95\% CI: 0.515-3.313\%) at lag03, respectively. No significant associations were found for $\mathrm{PM}_{2.5}$ and $\mathrm{O}_{3}$. Subgroup analysis demonstrated that females were more susceptible to $\mathrm{PM}_{2.5}, \mathrm{PM}_{10}, \mathrm{SO}_{2}$, and $\mathrm{NO}_{2}$. The concentrations of $\mathrm{PM}_{10}, \mathrm{SO}_{2}$, and $\mathrm{NO}_{2}$ were significantly associated with COPD mortality for older adults. The effects of $\mathrm{PM}_{2.5}$ and $\mathrm{O}_{3}$ on COPD mortality were higher in warm period. In two-pollutant models, the significantly positive associations between $\mathrm{SO}_{2}$ and $\mathrm{NO}_{2}$ and COPD mortality remained after adjusting for $\mathrm{PM}_{2.5}$ or $\mathrm{O}_{3}$. In conclusions, short-term exposure to $\mathrm{PM}_{10}, \mathrm{SO}_{2}$, and $\mathrm{NO}_{2}$ are significantly associated with a higher risk of COPD mortality. Female or elderly are more susceptible to air pollution. It is urgent to implement the environmental protection policy.
\end{abstract}

Keywords Ambient $\cdot$ Air pollution $\cdot$ Short-term effects $\cdot$ COPD $\cdot$ Mortality $\cdot$ Time-series

Yaqiong Yan and $\mathrm{Lu}$ She contributed equally to this work.

Responsible editor: Lotfi Aleya

Mei Yang

644593079@qq.com

$\triangle$ Liang Wang

519918393@qq.com

1 Wuhan Centers for Disease Control and Prevention, No.288 Machang Road, Wuhan, China

2 School of Medicine, Wuhan University of Science and Technology, No.947 Heping Road, Wuhan, China

3 Research Center for Health Promotion in Women, Youth and Children, Wuhan University of Science and Technology, Wuhan, China

\section{Background}

With the rapid development of modern industry and social economy, air pollution has become a common global problem that cannot be neglected in recent years. As a developing country, the magnitude of China is quite different from developed countries. Especially in several megacities, air pollution has become a major threat to public health. In 2010, air pollution is the fourth burden of disease in China, which leads to 1.234 million deaths and 250 million disability adjusted life yeas (DALY) (Yang et al. 2013). Wuhan, as the capital city of Hubei province, has a large population of about 11.21 million. The air pollution is severe because of the drastic urbanization and industrial expansion. During 2013 to 2017, average annual limits of $\mathrm{PM}_{10}, \mathrm{PM}_{2.5}$, and $\mathrm{NO}_{2}$ are 1.3 1.8, 1.5 2.7, and 1.2 1.5 times higher than the annual average acceptable limit, respectively (Yassin et al. 2019). Therefore, exploring the 
associations between ambient air pollution and health in Wuhan is of great importance.

Since the 1990s, numerous evidences have found that short-term exposure to ambient air pollution can increase the risk of adverse health, ranging from sub-health status to death, especially respiratory disorders (Khilnani and Tiwari 2018; Schraufnagel et al. 2019; Guan et al. 2016; Brugha and Grigg 2014). It is accepted that air pollution can disturb the function of respiratory system. Particulate matter may exert oxidative stress on cells in the lung by presenting or by stimulating the cells to produce reactive oxygen species (ROS) and inflammatory factors, and these play important roles in lung tissue injury (Tao et al. 2003; Goldsmith et al. 1997; Ghio and Andrew 1999). Chronic respiratory diseases cause a substantial health-care burden in China, and chronic obstructive pulmonary disease (COPD) is the third most common causes of mortality, with 910,809 deaths in 2013(Yang et al. 2013). Cohort and case crossover studies have shown that ambient air pollution has contributed to increased incidence and prevalence of COPD (Song et al. 2014). Among individuals with COPD, exposure to air pollution is associated with decreased lung function and increased respiratory symptoms (Doiron et al. 2019). The World Health Organization (WHO) estimates that ambient air pollution is responsible for 3.7 million of premature death worldwide in 2012, and $14 \%$ of these deaths are due to COPD or acute lower respiratory infections (WHO 2014). It is urgent to further investigate the effects of ambient air pollution exposure on COPD mortality.

Many researches have explored the health effects of air pollution with time-series methods (Astudillo-García et al. 2019; Guo et al. 2017; Katsouyanni et al. 1995; Luo et al. 2020; Mokoena et al. 2019), but few studies specifically measured the association between ambient air pollution and COPD mortality. Evidence on the short-term effects of ambient air pollution on COPD mortality is still not conclusive to date. Furthermore, the characteristics of air pollution in different regions vary substantially. Hence, the aim of this study was to investigate the associations between the concentrations of ambient $\mathrm{PM}_{2.5}, \mathrm{PM}_{10}, \mathrm{SO}_{2}, \mathrm{NO}_{2}$, and $\mathrm{O}_{3}$ and COPD mortality in Wuhan, China.

\section{Methods}

\section{Data collection}

Death counts between January 1, 2014, and December 31, 2019, were obtained from Mortality Register System in the Wuhan Center for Disease Control and Prevention. For this analysis, we selected the deaths due to COPD, which were classified according to the International Statistical Classification of Disease, 10th Revision codes (ICD-10: J40J44, I27.9). In view of the vast majority of pulmonary heart diseases (I27.9) caused by chronic bronchitis and emphysema, few were caused by pulmonary embolism, primary pulmonary hypertension, kyphoscoliotic heart disease, and so on; hence, all pulmonary heart diseases were included in COPD. The information of date of death, cause of death, sex, and age was collected. Because the death data were surveillance data, there was no requirement for informed consent. This study was approved by the Ethical Committee of the Wuhan Center for Disease Control and Prevention and was conducted in compliance with the tenets of the Declaration of Helsinki. The results were reported according to the STORBE statement.

Wuhan is located in central China $\left(29^{\circ} 58^{\prime}-31^{\circ} 22 \mathrm{~N}, 113^{\circ}\right.$ $41^{\prime}-115^{\circ} 05^{\prime} \mathrm{E}$ ), with an area of $8569 \mathrm{~km}^{2}$. Ten national air quality monitoring stations have been established. In this study, daily average concentrations of air pollutants including $\mathrm{PM}_{2.5}$ (mass of particles with aerodynamic diameter $<2.5 \mu \mathrm{m}$ ), $\mathrm{PM}_{10}$ (mass of particles with aerodynamic diameter $<10 \mu \mathrm{m}$ ), $\mathrm{SO}_{2}$ (sulfur dioxide), $\mathrm{NO}_{2}$ (nitrogen dioxide), and $\mathrm{O}_{3}$ (ground-level ozone) during January 1, 2014, to December 31, 2019, were obtained from the Wuhan Ecology and Environmental Bureau.

Daily meteorological data, including daily mean temperature, atmospheric pressure, and relative humidity during the same period, were obtained from the Wuhan Meteorological Administration.

\section{Statistical analysis}

Daily COPD mortality, air pollutants, and meteorological data were described as mean, standard deviation (SD), and quartile. Spearman's correlation was used to estimate the associations between air pollutants and meteorological factors.

For the time-series analysis, daily COPD mortality data was low, belonging to small probability event and approximately followed the Poisson distribution. Therefore, generalized additive Poisson regression with a log-link function was conducted to assess the association between daily counts of COPD mortality and air pollutant concentrations. The model is as below:

$$
\begin{aligned}
\log [\mathrm{E}(\mathrm{Yt})]= & \alpha+\beta X t+D O W+\text { Holiday }+s(\text { time }, d f) \\
& +s(Z t, d f)
\end{aligned}
$$

In this equation, $t$ refers to the day of the observation; $Y t$ is the observed daily death counts on day $t ; E(Y t)$ is the expected daily death count on day $t ; \alpha$ is the intercept of the model; $\beta$ represents the regression coefficient for each air pollutant; $X t$ is the concentration of air pollutant at day $t ; Z t$ represents meteorological data at day $t$; DOW is the dummy variable for day of the week; Holiday is the dummy variable for day of the holiday; and $s$ is the smoothing spline function for the nonlinear variables such as temperature, humidity, 
atmospheric pressure, and calendar time. We used the value of Akaike information criterion (AIC) to determine the degrees of freedom $(d f)$, and the smaller AIC value indicated the preferred model. Finally, we selected $7 d f$ per year for the time to adjust the time trend and seasonality, and $3 d f$ were used for temperature, humidity, and atmospheric pressure. Regarding the concentrations of air pollutants, we estimated the associations with different lag structures using single lag from the current day up to the previous 5 days (lag0-lag5), as well as moving averages of the current and previous days (lag01lag05). For meteorological data, the current day measurement was adopted in all lag structures. After the working model was built, the air pollutants were included separately. Subgroup analyses by age $(<65, \geq 65)$, sex (males, females), and season (cold period (from May to October), warm period (from November to April)) were also conducted. Elderly was defined as older than 65 years old. Furthermore, we used twopollutant models for all pollutants without interactions to determine the possible role of single pollutants.

The association between air pollutants and COPD mortality was reported as excess relative risk (ERR) with $95 \%$ confidence interval $(\mathrm{CI})$ for $10 \mu \mathrm{g} / \mathrm{m}^{3}$ increase in $\mathrm{PM}_{2.5}, \mathrm{PM}_{10}, \mathrm{SO}_{2}$, $\mathrm{NO}_{2}$, and $\mathrm{O}_{3}$ concentrations. All statistical analyses were performed using R (version 4.0.2) packages "mgcv" and "nlme." Statistical significance was defined as a two-tailed $P<0.05$.

\section{Results}

Table 1 presented the descriptive statistics for daily number of COPD death, air pollutants, and meteorological data from January 1, 2014, to December 31, 2019. During the 6-year period, there were 16,150 deaths (7.37 deaths per day) from COPD in Wuhan. Daily death counts were higher in males than in females (4.81 vs. 2.56 deaths per day). $92.28 \%$ deaths were elderly, and the daily death count was 6.80 . The daily mean concentrations of $\mathrm{PM}_{2.5}, \mathrm{PM}_{10}, \mathrm{SO}_{2}, \mathrm{NO}_{2}$, and $\mathrm{O}_{3}$ were 59.03, 90.48, 12.91, 48.84, and $91.77 \mu \mathrm{g} / \mathrm{m}^{3}$, respectively. And the average of atmospheric pressure, relative humidity, and daily temperature were $1013.10 \mathrm{kPa}, 79.42 \%$, and $17.18^{\circ} \mathrm{C}$.

The daily concentrations of $\mathrm{PM}_{2.5}, \mathrm{PM}_{10}, \mathrm{SO}_{2}$, and $\mathrm{NO}_{2}$ were strongly and positively correlated with each other, as shown in Table 2 . In contrast, the daily concentrations of $\mathrm{O}_{3}$ were moderately and negatively correlated with those of the other pollutants. In addition, air pressure was positive, and temperature was negatively correlated with all air pollutants except for $\mathrm{O}_{3}\left(r_{\text {hpa-O3 }}=-0.55, P<0.001 ; r_{\text {tem }-\mathrm{O} 3}=0.68\right.$, $P<0.001)$. Relative humidity was negatively correlated with the five air pollutants $(P<0.01)$.

Figure 1 showed the time trends for air pollutants, and all showed relatively stable seasonal trends annually. The concentrations of $\mathrm{PM}_{2.5}, \mathrm{PM}_{10}, \mathrm{SO}_{2}$, and $\mathrm{NO}_{2}$ had similar characteristics of periodic fluctuation, which were higher in the cold season and lower in the warm season. However, the concentrations of $\mathrm{O}_{3}$ showed an inverse trend. The daily concentrations of $\mathrm{PM}_{2.5}$ and $\mathrm{SO}_{2}$ during 2017 to 2019 were lower than those of previous years. COPD mortality in the study period also showed a seasonal pattern with higher counts in winter and lower counts in summer.

Table 3 illustrated the EERs of COPD mortality for every $10 \mu \mathrm{g} / \mathrm{m}^{3}$ increase of air pollutant concentrations with different lag days in single pollutant models. All the five pollutants were positively associated with COPD mortality. However,
Table 1 Descriptive statistics of daily mortality counts, air pollutant concentrations, and meteorological parameters in Wuhan, China, during 2014 2019

\begin{tabular}{|c|c|c|c|c|c|c|}
\hline Variables & Mean (SD) & Min & $\mathrm{P} 25$ & $\mathrm{P} 50$ & P75 & Max \\
\hline \multicolumn{7}{|l|}{ Number of COPD deaths } \\
\hline Total & $7.37(3.56)$ & 0 & 5 & 7 & 9 & 21 \\
\hline Males & $4.81(2.57)$ & 0 & 3 & 4 & 6 & 16 \\
\hline Females & $2.56(1.88)$ & 0 & 1 & 2 & 4 & 12 \\
\hline$<65$ years & $0.57(0.79)$ & 0 & 0 & 0 & 1 & 4 \\
\hline$\geq 65$ years & $6.80(3.35)$ & 0 & 4 & 6 & 9 & 21 \\
\hline \multicolumn{7}{|l|}{ Air pollutants } \\
\hline $\mathrm{PM}_{2.5}\left(\mu \mathrm{g} / \mathrm{m}^{3}\right)$ & $59.03(40.20)$ & 5.00 & 31.23 & 48.62 & 75.62 & 300.89 \\
\hline $\mathrm{PM}_{10}\left(\mu \mathrm{g} / \mathrm{m}^{3}\right)$ & $90.48(50.28)$ & 7.56 & 53.00 & 81.56 & 117.78 & 532.00 \\
\hline $\mathrm{SO}_{2}\left(\mu \mathrm{g} / \mathrm{m}^{3}\right)$ & $12.91(10.23)$ & 2.33 & 6.22 & 10.00 & 15.56 & 101.33 \\
\hline $\mathrm{NO}_{2}\left(\mu \mathrm{g} / \mathrm{m}^{3}\right)$ & $48.84(20.60)$ & 9.78 & 32.93 & 45.00 & 61.20 & 125.33 \\
\hline $\mathrm{O}_{3}\left(\mu \mathrm{g} / \mathrm{m}^{3}\right)$ & $91.77(50.43)$ & 5.33 & 51.00 & 85.33 & 128.00 & 261.50 \\
\hline \multicolumn{7}{|l|}{ Meteorological variables } \\
\hline Air pressure $(\mathrm{kPa})$ & $1013.10(9.40)$ & 993.50 & 1004.90 & 1013.10 & 1020.40 & 1043.00 \\
\hline Relative humidity (\%) & $79.42(10.27)$ & 41.00 & 73.00 & 80.00 & 87.00 & 100.00 \\
\hline Temperature $\left({ }^{\circ} \mathrm{C}\right)$ & $17.18(9.16)$ & -3.80 & 9.10 & 18.15 & 24.90 & 33.90 \\
\hline
\end{tabular}


Table 2 Spearman's correlation between air pollutants and meteorological factors in Wuhan, China, during 2013-2019

\begin{tabular}{|c|c|c|c|c|c|c|c|c|}
\hline & $\mathrm{PM}_{2.5}$ & $\mathrm{PM}_{10}$ & $\mathrm{SO}_{2}$ & $\mathrm{NO}_{2}$ & $\mathrm{O}_{3}$ & Air pressure & Relative humidity & Temperature \\
\hline $\mathrm{PM}_{2.5}$ & 1.00 & & & & & & & \\
\hline $\mathrm{PM}_{10}$ & $0.84^{\mathrm{a}}$ & 1.00 & & & & & & \\
\hline $\mathrm{SO}_{2}$ & $0.68^{\mathrm{a}}$ & $0.73^{\mathrm{a}}$ & 1.00 & & & & & \\
\hline $\mathrm{NO}_{2}$ & $0.70^{\mathrm{a}}$ & $0.77^{\mathrm{a}}$ & $0.72^{\mathrm{a}}$ & 1.00 & & & & \\
\hline $\mathrm{O}_{3}$ & $-0.22^{\mathrm{a}}$ & $-0.08^{\mathrm{a}}$ & -0.03 & $-0.07^{\mathrm{b}}$ & 1.00 & & & \\
\hline Air pressure & $0.49^{\mathrm{a}}$ & $0.29^{\mathrm{a}}$ & $0.41^{\mathrm{a}}$ & $0.38^{\mathrm{a}}$ & $-0.55^{\mathrm{a}}$ & 1.00 & & \\
\hline Relative humidity & $-0.07^{\mathrm{b}}$ & $-0.36^{\mathrm{a}}$ & $-0.37^{\mathrm{a}}$ & $-0.15^{\mathrm{a}}$ & $-0.44^{\mathrm{a}}$ & -0.04 & 1.00 & \\
\hline Temperature & $-0.53^{\mathrm{a}}$ & $-0.26^{\mathrm{a}}$ & $-0.37^{\mathrm{a}}$ & $-0.38^{\mathrm{a}}$ & $0.68^{\mathrm{a}}$ & $-0.91^{\mathrm{a}}$ & $-0.12^{\mathrm{a}}$ & 1.00 \\
\hline
\end{tabular}

for the single-day lag effects, positive significant associations were observed only for $\mathrm{SO}_{2}$ at lag1 and lag 2, $\mathrm{NO}_{2}$ at lag 1 and lag2, and $\mathrm{O}_{3}$ at lag 3. The effects of the five pollutants on COPD mortality were highest at lag0 for PM2.5 (ERR: $0.472 \%$, 95\% CI: $-0.059 \sim 1.006$ ), at lag 1 for $\mathrm{PM}_{10}$ (ERR: $0.384 \%$, 95\% CI: $-0.002 \sim 0.771$ ) and $\mathrm{SO}_{2}$ (ERR: $2.958 \%$, 95\% CI: $0.665 \sim 5.303$ ), at lag 2 for $\mathrm{NO}_{2}$ (ERR: $1.331 \%$, 95\% CI: 0.368 2.302), and at lag3 for $\mathrm{O}_{3}$ (ERR: $0.500 \%$, 95\% CI: $0.033 \sim 0.970)$. The effects of moving average lags were higher than single lags in different period. For the moving averages, positive significant associations were observed for $\mathrm{PM}_{10}$ at lag02 and lag03, $\mathrm{SO}_{2}$ at lag01-lag03, and $\mathrm{NO}_{2}$ at lag02-lag05. All pollutants showed the strongest estimates at lag03. For each increase of $10 \mu \mathrm{g} / \mathrm{m}^{3}$ in $\mathrm{PM}_{2.5}, \mathrm{PM}_{10}, \mathrm{SO}_{2}$, $\mathrm{NO}_{2}$, and $\mathrm{O}_{3}$ concentrations, COPD mortality increased by $0.520 \%$ (95\% CI: $-0.217 \sim 1.263$ ), $0.583 \%$ (95\% CI: $0.055 \sim 1.113$ ), $4.299 \%$ (95\% CI: $0.978 \sim 7.729), 1.816 \%$ (95\% CI: $0.515 \sim 3.133$ ), and $0.495 \%$ (95\% CI: $-0.226 \sim 1.222$ ) at lag03, respectively. The sensitive analysis was conducted by generalized additive Quasi-Poisson regression with a log-link function, and the results did not find great changes in the EERs (supplement Table 1).

The effects of the individual air pollutants on subjects by sex and age were performed in Fig. 2. $\mathrm{SO}_{2}$ had the greatest impact on each subgroup analysis. $\mathrm{PM}_{2.5}, \mathrm{PM}_{10}, \mathrm{SO}_{2}$, and $\mathrm{NO}_{2}$ estimates of females were higher than those for males, except for $\mathrm{PM}_{2.5}$ at lag5, $\mathrm{SO}_{2}$ at lag 3 , and $\mathrm{NO}_{2}$ at lag 1 , lag2 as well as lag01-lag03. In contrast, the associations of $\mathrm{O}_{3}$ were higher for males than females. Except for $\mathrm{O}_{3}$, all pollutant estimates of $<65$ year group was higher than those for older adults, but the estimates of $<65$ year group were almost nonsignificant (except for $\mathrm{PM}_{2.5}$ at lag2, $\mathrm{SO}_{2}$ at lag2 and lag3, and $\mathrm{NO}_{2}$ at lag3). For older adults, significant positive associations were observed for $\mathrm{PM}_{10}$ at lag1 and lag01-lag03; $\mathrm{SO}_{2}$ at lag1, lag2, as well as lag01-lag03; and $\mathrm{NO}_{2}$ at lag1, lag2, as well as lag02-lag04. As for seasonal effects, the effects of $\mathrm{PM}_{2.5}$ and $\mathrm{O}_{3}$ on COPD mortality were higher in warm period than cold period.
Figure 3 summarized the ERRs for COPD mortality associated with every $10 \mu \mathrm{g} / \mathrm{m}^{3}$ increase of air pollutant concentrations in two pollutant models at lag03. The estimates for $\mathrm{SO}_{2}$ and $\mathrm{NO}_{2}$ were the most stable across all two-pollutant models. In contrast, the estimates of $\mathrm{PM}_{2.5}, \mathrm{PM}_{10}$, and $\mathrm{O}_{3}$ decreased after the inclusion of $\mathrm{SO}_{2}$ or $\mathrm{NO}_{2}$. Additionally, the estimates of $\mathrm{PM}_{2.5}$ decreased after the inclusion of $\mathrm{PM}_{10}$. The significant positive associations between $\mathrm{SO}_{2}$ and $\mathrm{NO}_{2}$ and COPD mortality remained after adjusting for $\mathrm{PM}_{2.5}$ or $\mathrm{O}_{3}$.

\section{Discussion}

In our study, a population-based time-series model was used to investigate the associations between short-term air pollutants $\left(\mathrm{PM}_{2.5}, \mathrm{PM}_{10}, \mathrm{SO}_{2}, \mathrm{NO}_{2}\right.$, and $\left.\mathrm{O}_{3}\right)$ exposure and COPD mortality in Wuhan, China, during January 1, 2014, to December 31, 2019. The results showed that the concentrations of $\mathrm{PM}_{10}, \mathrm{SO}_{2}$, and $\mathrm{NO}_{2}$ were significantly positively associated with COPD mortality.

During 2014 to 2019, the levels of ambient air pollution were relatively high in Wuhan, China. The daily mean concentrations of $\mathrm{PM}_{2.5}\left(59.03 \mu \mathrm{g} / \mathrm{m}^{3}\right), \mathrm{PM}_{10}\left(90.48 \mu \mathrm{g} / \mathrm{m}^{3}\right)$, and $\mathrm{NO}_{2}\left(48.84 \mu \mathrm{g} / \mathrm{m}^{3}\right)$ exceeded the values of the WHO Air Quality Guidelines $\left(10,20\right.$, and $40 \mu \mathrm{g} / \mathrm{m}^{3}$, respectively). And the daily mean concentrations of $\mathrm{SO}_{2}$ and $\mathrm{O}_{3}$ were 12.91 and $91.77 \mu \mathrm{g} / \mathrm{m}^{3}$, which were within the Air Quality Guidelines values $\left(20,100 \mu \mathrm{g} / \mathrm{m}^{3}\right.$ respectively). The concentrations of air pollutants showed relatively stable trends. $\mathrm{PM}_{2.5}, \mathrm{PM}_{10}, \mathrm{SO}_{2}$, and $\mathrm{NO}_{2}$ peaked in winter. It was probable that coal-burning was still the important source of heat and energy in China. Furthermore, in winter, the dispersion of pollutants was poor. However, $\mathrm{O}_{3}$ was mostly formed by the conversion of nitrogen oxides and volatile organic compounds under high temperature, sufficient sunshine, and low humidity, which finally led to the peak values of $\mathrm{O}_{3}$ in summer. By the end of 2019, the number of motor vehicles exceeded 3.3 


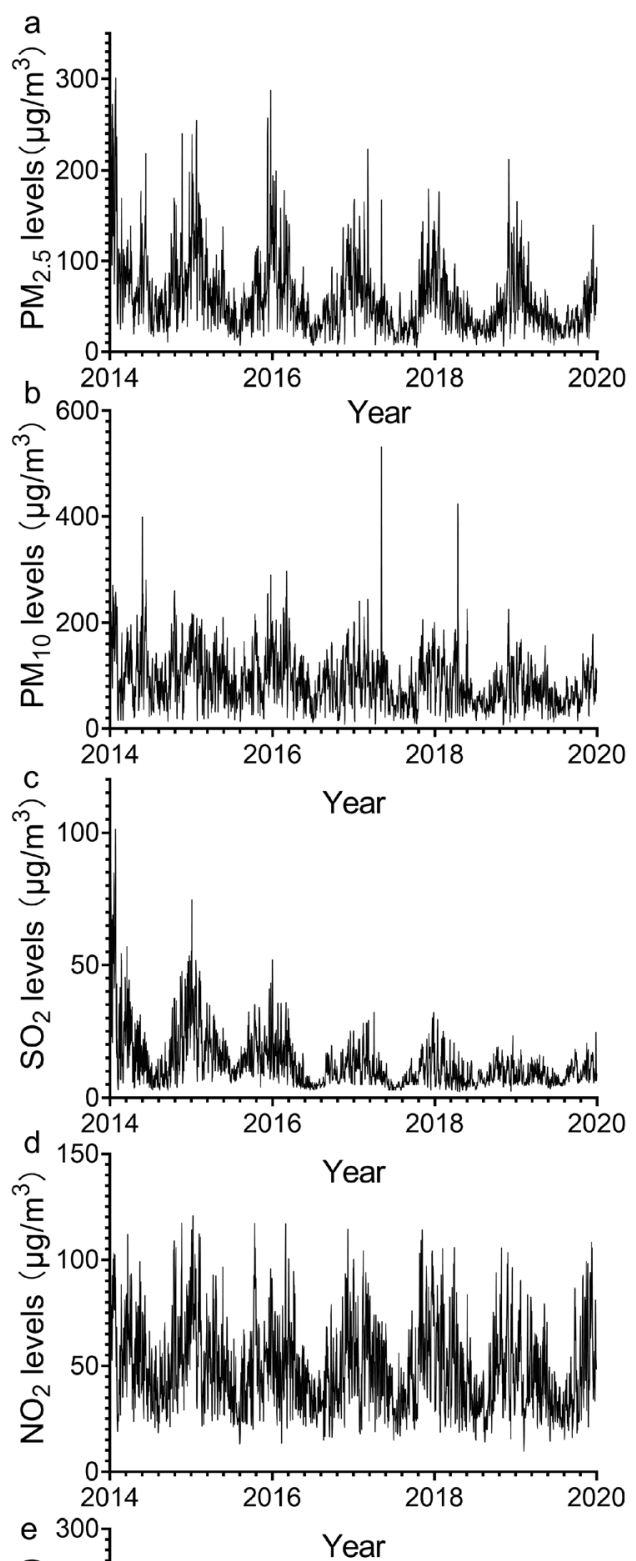

Fig. 1 Time-series of PM2.5 (a), $\mathrm{PM} 10$ (b), $\mathrm{SO}_{2}(\mathbf{c}), \mathrm{NO}_{2}(\mathbf{d})$, and $\mathrm{O}_{3}(\mathbf{e})$ and chronic obstructive pulmonary disease mortality (f) in Wuhan, China, during 2014-2019

million in Wuhan, and vehicle emission also became one of the major sources of environmental air pollution.

Our results showed that ambient air pollutants were positively associated with COPD mortality in single pollutant models. The effects on COPD mortality peaked within 4 days (lag03), and the strongest association was observed for $\mathrm{SO}_{2}$. An increase of $10 \mu \mathrm{g} / \mathrm{m}^{3}$ of $\mathrm{PM}_{10}$ was associated with a 0.583\% (95\% CI: $0.055-1.113 \%$ ) increase in COPD mortality. Moolgavkar et.al reported a significantly positive association between $\mathrm{PM}_{10}$ and the risk of COPD mortality with an increase of 2.66\% (95\% CI: $0.12-5.20 \%$ ) in COPD mortality per $25 \mu \mathrm{g} / \mathrm{m}^{3}$ increase in $\mathrm{PM}_{10}$ (Moolgavkar 2000). And a meta-analysis by $\mathrm{Zhu}$ et al. also concluded that a $10 \mu \mathrm{g} / \mathrm{m}^{3}$ increase in $\mathrm{PM}_{10}$ was associated with a $1.1 \%$ (95\% CI: 0.81.4\%) increase in COPD mortality (Zhu et al. 2013), while a case-crossover study in Cook city showed a lack of association between $\mathrm{PM}_{10}$ and the risk of death from COPD (Bateson and Schwartz 2004). We did not find significant associations between the concentrations of $\mathrm{PM}_{2.5}$ and COPD mortality, consistent with the results of a large population-based cohort study in Metropolitan Vancouver, Canada (Wen et al. 2013), which speculated that these null associations might reflect the lack of spatial variability of $\mathrm{PM}_{2.5}$ in intraurban study. But a meta-analysis concluded that a $10 \mu \mathrm{g} / \mathrm{m}^{3}$ increase in daily $\mathrm{PM}_{2.5}$ was associated with a $2.5 \%$ (95\% CI: $\left.1.5-3.5 \%\right)$ increase in COPD mortality (Yang et al. 2016). And in a COPD cohort, Faustini et al. found that effects on respiratory mortality among COPD subjects were particularly elevated 11.6\% (95\% CI: 2.0-22.2\%) from $\mathrm{PM}_{2.5}$ per $11 \mu \mathrm{g} / \mathrm{m}^{3}$ increase (Faustini et al. 2012). The source of $\mathrm{PM}_{2.5}$ varied in different cities which might be contributed to this inconsistence. The correlations between $\mathrm{PM}_{2.5}$ exposure and $\mathrm{COPD}$ mortality should be further confirmed in other cities.

Interestingly, our findings demonstrated that gaseous pollutants had stronger effects on COPD mortality than particulate matter. Similarly, other studies also suggested that compared to particulate matter, gaseous pollutant had stronger effects on COPD exacerbation and daily outpatient visits of respiratory diseases (Cheng et al. 2018; Li et al. 2016). Our estimates showed that a $10 \mu \mathrm{g} / \mathrm{m}^{3}$ increase of $\mathrm{NO}_{2}$ was significantly associated with a $1.816 \%$ (95\% CI: $0.515-3.133 \%)$ increase in COPD mortality. In a 6-year cohort study including all residents aged 51-90 years in Oslo, Norway, the results found that the concentrations of $\mathrm{NO}_{2}$ on COPD mortality appeared to have significantly linear effects (Næss et al. 2007), while Hart et al. found positive but nonsignificant associations of COPD mortality with $\mathrm{NO}_{2}, \mathrm{PM}_{2.5}$, and $\mathrm{SO}_{2}$ exposure in industry workers (Hart et al. 2011). 
Table 3 Estimated excess relative risks (ERRs) and $95 \%$ confidence intervals $(95 \% \mathrm{CI})$ of daily death from chronic obstructive pulmonary disease for a $10 \mu \mathrm{g} / \mathrm{m}^{3}$ increase in air pollutant's concentrations with different lag days in single pollutant models

\begin{tabular}{llllll}
\hline Lag days & $\mathrm{PM}_{2.5}$ & $\mathrm{PM}_{10}$ & $\mathrm{SO}_{2}$ & $\mathrm{NO}_{2}$ & $\mathrm{O}_{3}$ \\
\hline Lag0 & $0.472(-0.059,1.006)$ & $0.262(-0.137,0.662)$ & $0.986(-1.354,3.382)$ & $0.566(-0.341,1.481)$ & $-0.117(-0.650,0.419)$ \\
Lag1 & $0.286(-0.241,0.816)$ & $0.384(-0.002,0.771)$ & $2.958(0.665,5.303)^{\mathrm{b}}$ & $1.036(0.064,2.019)^{\mathrm{b}}$ & $0.212(-0.296,0.723)$ \\
Lag2 & $0.141(-0.375,0.660)$ & $0.320(-0.054,0.695)$ & $2.675(0.458,4.942)^{\mathrm{b}}$ & $1.331(0.368,2.302)^{\mathrm{a}}$ & $0.284(-0.190,0.763)$ \\
Lag3 & $0.320(-0.195,0.837)$ & $0.230(-0.138,0.599)$ & $1.465(-0.711,3.688)$ & $0.844(-0.077,1.773)$ & $0.500(0.033,0.970)^{\mathrm{b}}$ \\
Lag4 & $-0.258(-0.769,0.256)$ & $-0.133(-0.495,0.231)$ & $-0.859(-2.976,1.305)$ & $-0.168(-1.062,0.734)$ & $-0.141(-0.603,0.324)$ \\
Lag5 & $-0.481(-0.997,0.038)$ & $-0.105(-0.467,0.259)$ & $-0.863(-2.977,1.298)$ & $0.163(-0.727,1.060)$ & $-0.034(-0.496,0.430)$ \\
Lag01 & $0.467(-0.141,1.079)$ & $0.422(-0.027,0.874)$ & $2.765(0.034,5.570)^{\mathrm{b}}$ & $1.012(-0.040,2.075)$ & $0.063(-0.565,0.696)$ \\
Lag02 & $0.429(-0.246,1.108)$ & $0.535(0.044,1.029)^{\mathrm{b}}$ & $4.009(0.958,7.151)^{\mathrm{a}}$ & $1.566(0.378,2.768)^{\mathrm{a}}$ & $0.260(-0.420,0.944)$ \\
Lag03 & $0.520(-0.217,1.263)$ & $0.583(0.055,1.113)^{\mathrm{b}}$ & $4.299(0.978,7.729)^{\mathrm{b}}$ & $1.816(0.515,3.133)^{\mathrm{a}}$ & $0.495(-0.226,1.222)$ \\
Lag04 & $0.372(-0.423,1.172)$ & $0.466(-0.092,1.027)$ & $3.448(-0.073,7.094)$ & $1.598(0.207,3.010)^{\mathrm{b}}$ & $0.334(-0.424,1.098)$ \\
Lag05 & $0.159(-0.691,1.017)$ & $0.389(-0.199,0.979)$ & $2.833(-0.895,6.702)$ & $1.555(0.079,3.053)^{\mathrm{b}}$ & $0.280(-0.516,1.082)$ \\
\hline
\end{tabular}

${ }^{\mathrm{a}} P<0.01$

${ }^{\mathrm{b}} P<0.05$

$\mathrm{SO}_{2}$ mainly came from burning of fossil fuels. With the promotion of clean fuels in Wuhan recently, the concentration of $\mathrm{SO}_{2}$ gradually decreased The mean concentration of $\mathrm{SO}_{2}$ in Wuhan was $12.91 \mu \mathrm{g} / \mathrm{m}^{3}$, which could be considered as low level compared with many other Chinese cities (Guan et al. 2016; Zhang et al. 2019; Zhang et al. 2017). But our results showed that every increase of $10 \mu \mathrm{g} / \mathrm{m}^{3}$ of $\mathrm{SO}_{2}$ was associated with $4.299 \%$ (95\% CI: $0.978-7.729 \%$ ) increase in COPD mortality, which was higher than the values reported in several previous studies (Kan and Chen 2003). And Zhang et al. also demonstrated that $\mathrm{SO}_{2}$ had a stronger effect on cardiovascular mortality in Hefei, China (Zhang et al. 2017). The reason for this phenomenon was still unclear, but Samoli et al. found that when the concentration of $\mathrm{SO}_{2}$ is at a lower level, the impact of $\mathrm{SO}_{2}$ to mortality was greater (Samoli et al. 2001), which might partially explain the effects of $\mathrm{SO}_{2}$ in our study. Furthermore, similar with the results of a meta-analysis, we did not find significant associations between the concentrations of $\mathrm{O}_{3}$ and COPD mortality ( $\mathrm{Li}$ et al. 2016). To sum up, the inconformity with our findings might be due to the different chemical compositions of $\mathrm{PM}_{10}$ or $\mathrm{PM}_{2.5}$ in different areas, which could result in different effects on COPD mortality. In addition, the meteorological factors might influence the effects of air pollutants, but the compositions of air pollutants and meteorological conditions varied in different regions (Jordi and Xavier 2001). Moreover, the age, socioeconomic status and education level, and so on were able to modify the effects of air pollutants.

Although the mechanical explanation of adverse effects of ambient air pollution on COPD mortality remains unclear, identifying the associations of ambient air pollution in different exposure windows is of great importance in the estimation of health risk. In our study, we found that exposure to air pollutants at lag03 yielded the strongest estimates on COPD mortality. Another time-series study in Hefei, China also found the similar phenomenon in the associations between ambient air pollution and cardiovascular mortality (Zhang et al. 2017).

Subgroup analysis showed that females seemed to suffer more risk of COPD mortality from ambient air pollution. In addition, the results showed that the air pollution estimates of $<65$ year group were higher than those for older adults, though the estimates were almost nonsignificant. Only $7.2 \%$ in our study were $<65$ year group; the sample size might be a strong confounder. A population-based cohort study also showed that the relative risks for COPD mortality associated with a $0.78 \mu \mathrm{g} / \mathrm{m}^{3}$ elevation in black carbon concentrations were 1.06 (95\% CI: 0.97-1.15) and 1.08 (95\% CI: 0.97-1.20) for males and females and 1.31 (95\% CI: 1.07-1.60) and 1.04 (95\% CI: $0.97-1.12$ ) for $<65$ and $\geq 65$ year groups (Wen et al. 2013), similar with the results from a population-based UK Biobank study, which concluded that the adverse effects of $\mathrm{PM}_{2.5}$ and $\mathrm{NO}_{2}$ on COPD prevalence were stronger in females (Doiron et al. 2019). However, Naess et al documented that males were more susceptible to air pollution $\left(\mathrm{PM}_{10}, \mathrm{PM}_{2.5}, \mathrm{SO}_{2}\right)$ than females (Næss et al. 2007). The reasons for our genderspecific findings were still unclear and needed further investigation. Furthermore, the concentrations of $\mathrm{PM}_{10}, \mathrm{SO}_{2}$, and $\mathrm{NO}_{2}$ were significantly associated with COPD mortality for older adults; effective public health prevention policies specified for older adults should be made to reduce the burden of COPD. Our results also demonstrated that the association between air pollutants and COPD mortality was stronger in the warm period than in cold period, partially consistent with the previous studies (Zhang et al. 2017; Tong et al. 2014). We speculated that the possible reasons of the inconsistence might 


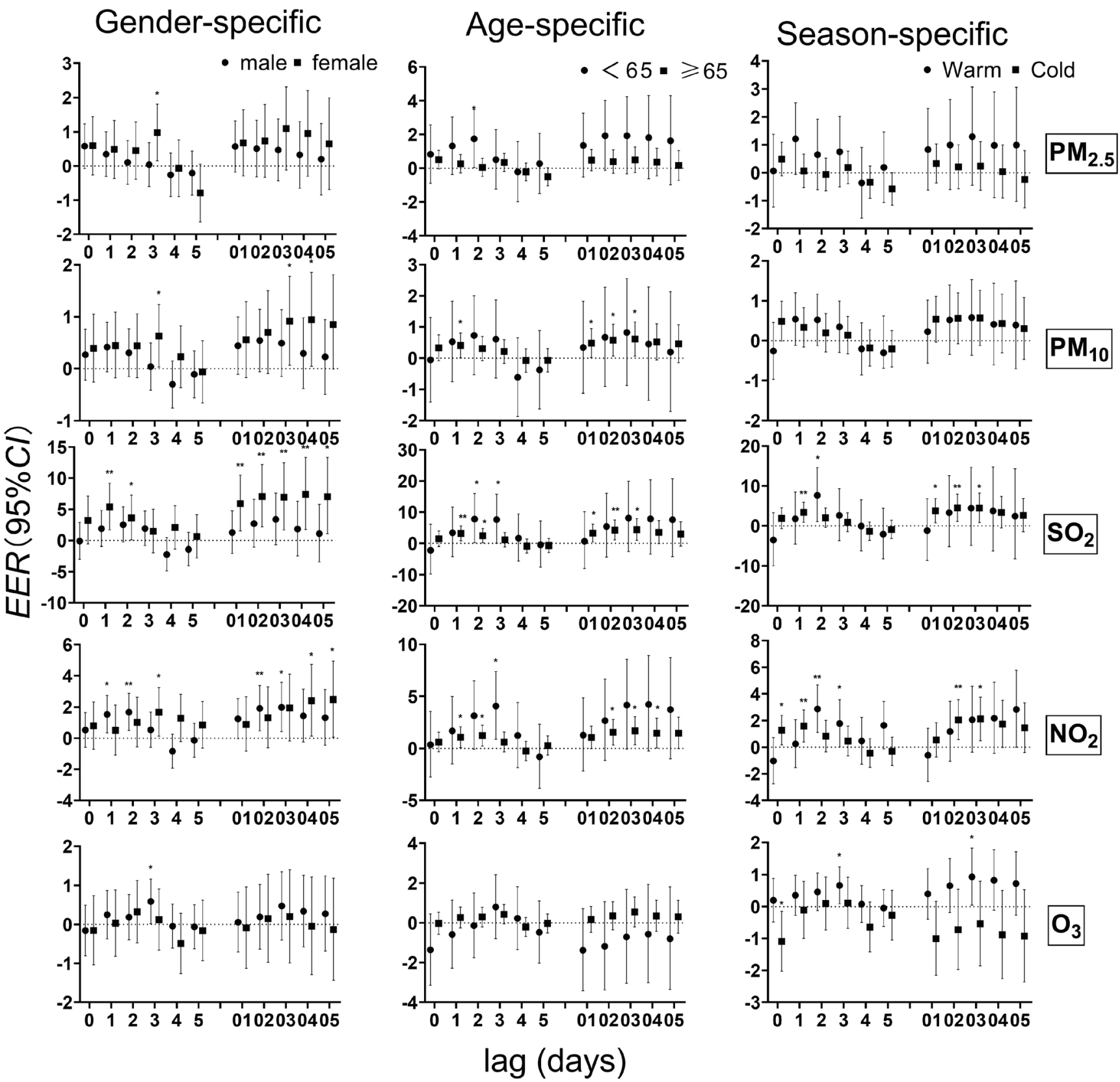

Fig. 2 Age-, gender-, and season-specific estimated excess relative risks (ERRs) and 95\% confidence intervals (95\% CI) for daily deaths from chronic obstructive pulmonary disease with a $10 \mu \mathrm{g} / \mathrm{m}^{3}$ increase in air pollutants using different lag days

due to the varied components of air pollutants in Wuhan in different season. In addition, the meteorological factors and pollutants were correlated with each other which might modify the correlation between air pollutants and COPD mortality.

Two-pollutant models were implemented in our study to explore the possible role of single pollutants. We concluded that the estimates of $\mathrm{PM}_{2.5}, \mathrm{PM}_{10}$, and $\mathrm{O}_{3}$ decreased after the inclusion of $\mathrm{SO}_{2}$ or $\mathrm{NO}_{2}$, consistent with the previous studies (Zhang et al. 2019; Nhung et al. 2018). These results revealed the relatively independent associations of $\mathrm{SO}_{2}$ and $\mathrm{NO}_{2}$. The associations of $\mathrm{SO}_{2}$ and $\mathrm{NO}_{2}$ on COPD mortality might better reflect the associations between air pollution and COPD mortality in Wuhan compared with other pollutants.

Though this study was a population-based time-series study which covered all population in Wuhan, there were some limitations. Firstly, the average of ten fixed sited monitoring data of air pollutant concentrations were used to infer exposures of individuals, which might lead to potential misclassification exposure and ignore the spatial impact of air pollution on COPD. Secondly, due to data unavailability, some factors including personal social information (such as tobacco use and body mass index) that could affect the effects 
Fig. 3 Estimated excess relative risks (ERRs) and $95 \%$ confidence intervals $(95 \% \mathrm{CI})$ for daily deaths from chronic obstructive pulmonary disease with a $10 \mu \mathrm{g} / \mathrm{m}^{3}$ increase in air pollutants using single- and two-pollutant models. Lag03 were used

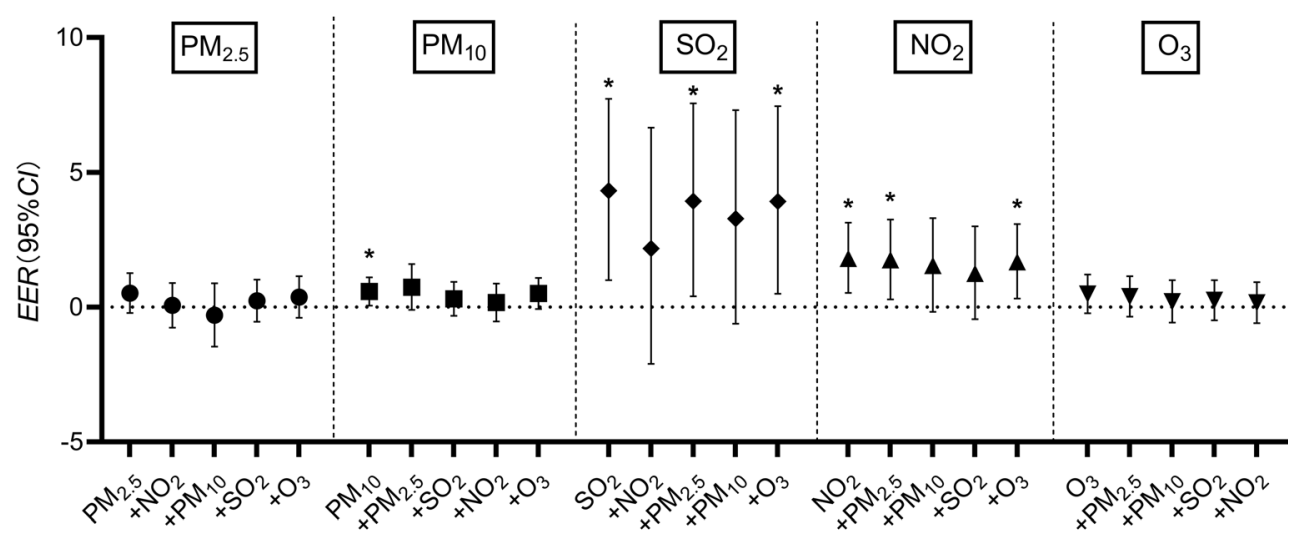

Two-pollutant models (Lag03) were not controlled. Hence, we could not rule out the nonrelevant death records due to obesity or other reasons than air pollution.

\section{Conclusions}

The results of this study suggested that exposure to $\mathrm{PM}_{10}$, $\mathrm{SO}_{2}$, and $\mathrm{NO}_{2}$ was significantly positively associated with a higher risk of COPD mortality in Wuhan, China. Moreover, female and elderly are more susceptible to air pollution. Our findings could provide evidences to help understand the adverse health effects of air pollution, which might have important implications for policy makers to curb and reduce ambient air pollution in Wuhan.

Supplementary Information The online version contains supplementary material available at https://doi.org/10.1007/s11356-021-13180-6.

Authors' contributions YY: conceptualization, methodology, and funding acquisition. LS: formal analysis and writing-original draft preparation. YG: software and funding acquisition. YZ: data curation. PZ: software. BX: validation. JZ: data curation. MY: writing (reviewing and editing), conceptualization, and funding acquisition. LW: conceptualization. All authors read and approved the final manuscript.

Funding This research was funded by the Basic Applied Research Project of Wuhan Science and Technology Bureau (grant number: 2015061701011631), Emergency Research Fund for Novel Coronavirus Pneumonia Prevention and Control of Wuhan Municipal Health Commission (grant number: EG20A04), Scientific Research Project of Hubei Provincial Health and Family Planning Commission (grant number: WJ2019F011), and Scientific Research Program of Hubei Education Department (grant number: B2020006). The funds of the study had no role in the study design, execution, analysis, data interpretation or writing of the report.

Data availability The datasets used and/or analyzed during the current study are available from the corresponding author on reasonable request.

\section{Declarations}

Ethics approval and consent to participate The death data were surveillance data; there was no requirement for informed consent. This study was approved by the Ethical Committee of the Wuhan Center for Disease Control and Prevention.

Consent for publication Not applicable.

Competing interests The authors declare no competing interests. Supplementary Information The online version contains supplementary material available at https://doi.org/10.1007/s11356-021-13180-6.

\section{References}

Astudillo-García CI, Rodríguez-Villamizar LA, Cortez-Lugo M, De La Cruz C, Fernández-Nio JA (2019) Air pollution and suicide in Mexico City: a time series analysis, 2000-2016. Int J Environ Res Public Health 16:2971

Bateson TF, Schwartz J (2004) Who is sensitive to the effects of particulate air pollution on mortality? A case-crossover analysis of effect modifiers. Epidemiology 15:143-149

Brugha R, Grigg J (2014) Urban air pollution and respiratory infections. Paediatr Respir Rev 15:194-199

Cheng Y, Tatiana E, Cao GY, Zheng X (2018) Health impacts of exposure to gaseous pollutants and particulate matter in Beijing - a nonlinear analysis based on the new evidence. Int J Environ Res Public Health 15:1969

Doiron D, De Hoogh K, Probsthensch N, Fortier I, Cai Y, De Matteis S, Hansell AL (2019) Air pollution, lung function and COPD: results from the population-based UK Biobank study. Eur Respir J 54: 1802140

Faustini A, Stafoggia M, Cappai G, Forastiere F (2012) Short-term effects of air pollution in a cohort of patients with chronic obstructive pulmonary disease. Epidemiology 24:177

Ghio, Andrew J (1999) Metals associated with both the water-soluble and insoluble fractions of an ambient air pollution particle catalyze an oxidative stress. Inhal Toxicol 11:37-49

Goldsmith CA, Frevert C, Imrich A, Sioutas C, Kobzik L (1997) Alveolar macrophage interaction with air pollution particulates. Environ Health Perspectives 105:1191-1195 
Guan WJ, Zheng XY, Chung KF, Zhong NS (2016) Impact of air pollution on the burden of chronic respiratory diseases in China: time for urgent action. Lancet 388:1939-1951

Guo Y, Ma Y, Zhang Y, Huang S, Wu Y, Yu S, Zou F, Cheng J (2017) 'Time series analysis of ambient air pollution effects on daily mortality. Environ Sci Pollut Res

Hart JE, Garshick E, Dockery DW, Smith TJ, Ryan L, Laden F (2011) Long-term ambient multipollutant exposures and mortality. Am J Respir Crit Care Med 183:73-78

Jordi S, Xavier B (2001) Particles, and not gases, are associated with the risk of death in patients with chronic obstructive pulmonary disease'. Int J Epidemiol 30:1138-1140

Kan H, Chen B (2003) A case-crossover analysis of air pollution and daily mortality in Shanghai. J Occup Health 45:119-124

Katsouyanni K, Zmirou D, Spix C, Sunyer J, Vigotti MA (1995) Shortterm effects of air pollution on health: a European approach using epidemiological time-series data. The APHEA project: background, objectives, design. Eur Respir J 8:1030-1038

Khilnani GC, Tiwari P (2018) Air pollution in India and related adverse respiratory health effects: past, present, and future directions. Curr Opinion Pulmonary Med 24:1

Li J, Sun S, Tang R, Qiu H, Huang Q, Tonya M, Tian L (2016) Major air pollutants and risk of COPD exacerbations: a systematic review and meta-analysis. Int J Chron Obstruct Pulmon Dis 11:3079-3091

Luo L, Dai Y, Zhang F, Chen M, Chen F, Fang Q (2020) Time series analysis of ambient air pollution effects on dynamic stroke mortality. Int J Health Plann Manag 35:79-103

Mokoena KK, Ethan CJ, Yu Y, Shale K, Liu F (2019) Ambient air pollution and respiratory mortality in Xi'an, China: a time-series analysis. Respir Res 20:139

Moolgavkar SH (2000) Air pollution and daily mortality in three U.S. counties. Environ Health Perspect 108:777-784

Næss Ø, Nafstad P, Aamodt G, Claussen B, Rosland P (2007) Relation between concentration of air pollution and cause-specific mortality: four-year exposures to nitrogen dioxide and particulate matter pollutants in 470 neighborhoods in Oslo, Norway. Am J Epidemiol 165:435-443

Nhung NTT, Schindler C, Dien TM, Probst-Hensch N, Perez L, Kuenzli $\mathrm{N}$ (2018) Acute effects of ambient air pollution on lower respiratory infections in Hanoi children: an eight-year time series study. Environ Int 110:139-148

Samoli E, Schwartz J, Wojtyniak B, Touloumi G, Spix C, Balducci F, Medina S, Rossi G, Sunyer J, Bacharova L (2001) Investigating regional differences in short-term effects of air pollution on daily mortality in the APHEA project: a sensitivity analysis for controlling long-term trends and seasonality. Environ Health Perspect 109:349353

Schraufnagel DE, Balmes JR, De Matteis S, Hoffman B, Wuebbles DJ (2019) Health benefits of air pollution reduction. Ann Am Thoracic Soc 16:1478-1487
Song Q, David C, Wang X, Ren J (2014) The global contribution of outdoor air pollution to the incidence, prevalence, mortality and hospital admission for chronic obstructive pulmonary disease: a systematic review and meta-analysis. Int J Environ Res Public Health 11:11822-11832

Tao F, Gonzalez-Flecha B, Kobzik L (2003) Reactive oxygen species in pulmonary inflammation by ambient particulates. Free Radical Biol Med 35:327-340

Tong L, Li K, Zhou Q (2014) Promoted relationship of cardiovascular morbidity with air pollutants in a typical Chinese urban area. PLoS One 9:e108076

Wen QG, Mark Fitzgerald J, Carlsten C, Sadatsafavi M, Brauer M (2013) Associations of ambient air pollution with chronic obstructive pulmonary disease hospitalization and mortality. Am J Respir Crit Care Med 187:721-727

WHO. 2014. 'WHO fact sheet on ambient (outdoor) air quality guidelines: includes key facts, definition, health effects, guideline values and WHO response'.

Yang G, Yu W, Zeng Y, Gao GF, Liang X, Zhou M, Wan X, Yu S, Jiang Y, Naghavi M (2013) Rapid health transition in China, 1990-2010: findings from the Global Burden of Disease Study 2010. Lancet 381:1987-2015

Yang J-W, Fan L-C, Xu J-F, Cao W-J, Choi A (2016) 'Short-term exposure to ambient fine particulate matter increases hospitalizations and mortality in COPD a systematic review and meta-analysis. Chest. 149(2):447-445

Yassin M, Jun Q, Zhengxuan Y, Fatuma N, Xiang Z (2019) Boundary layer perspective assessment of air pollution status in Wuhan city from 2013 to 2017. Environ Monit Assess 191(2):69

Zhang C, Ding R, Xiao C, Xu Y, Cheng H, Zhu F, Lei R, Di D, Zhao Q, Cao J (2017) Association between air pollution and cardiovascular mortality in Hefei, China: a time-series analysis. Environ Pollut 229: 790

Zhang, Wang J, Cao H, Sun D, Qi Z, Guo C, Peng W, Sun Y, Xie Y, Liu X, Li B, Luo Y, Pan Y, Li Y, Zhang L (2019) Associations between ambient air pollution and mortality from all causes, pneumonia, and congenital heart diseases among children aged under 5 years in Beijing, China: a population-based time series study. Environ Res 176:108531-108531

Zhu R, Chen Y, Wu S, Deng F, Yao W (2013) The relationship between particulate matter (PM10) and hospitalizations and mortality of chronic obstructive pulmonary disease: a meta-analysis. COPD 10: 307-315

Publisher's Note Springer Nature remains neutral with regard to jurisdictional claims in published maps and institutional affiliations. 